\title{
Evaluation Index System on Relationship between Urban Mass Rail Transit and Its Surrounding Land Use Based on TOD Mode
}

\author{
Chuan Ding ${ }^{1, a}$, Yaowu Wang ${ }^{1, b}$, Binglei Xie ${ }^{1, c}$ and Yaoyu Lin ${ }^{1, d}$ \\ ${ }^{1}$ Shenzhen Graduate School, Harbin Institute of Technology, Shenzhen, 518055, China \\ adingchuan@126.com, bwyw@hitsz.edu.cn, xiebinglei@126.com, 'linyy@hitsz.edu.cn
}

Keywords: Mass Rail Transit, Land Use, Relationship, TOD Mode, DEA Model

\begin{abstract}
To establish the evaluation index system on relationship between urban mass rail transit and its surrounding land use based on transit oriented development (TOD) mode, the suitable methods and principles of evaluation index system were analyzed. An evaluation procedure frame was proposed based on data envelopment analysis (DEA) model. Then the evaluation indexes from urban mass rail transit system and land use system selected based on interactive relations between urban mass rail transit and land use under TOD mode.
\end{abstract}

\section{Introduction}

There is complex interaction between urban transport and land use. Urban transport improves the accessibility to different regions, and makes a significant effect on land use, while land use is derived from the transportation generation ${ }^{[1]}$. Total transportation demand, with distribution of main traffic direction can be determined by land-use pattern and function layout ${ }^{[2]}$.

Currently, mass transit rail has become a sustainable mode in the face of more serious traffic congestion, energy consumption and traffic environment problems, etc. Many cities in China are constructing mass transit rail. Large-capacity, rapid-speed, and low-pollution rail transit meets not only the urban traffic demand, but also strengthens commerce, employment activities in the central city, therefore stimulates the formation of outskirts development along the rail route. In order to achieve the coordinated development between urban rail transit and its surrounding land use, a scientific and rational evaluation index system should be firstly built, and then coordinated development status can be determined, which can provide a theoretical basis on planning and construction adjustment for operational management.

Many scholars have done some researches on the relationship between transportation and land use. Chu constructed macro evaluation index system considering the characteristics of Beijing, where indexes were selected from three aspects, land intensive degree, efficiency and service level of transport system, and environmental quality ${ }^{[3]}$. Yang analyzed coordination of urban transportation and land use in 16 typical cities of China, and proposed a simply evaluation indexes based on TOD, however, the index system didn't embody the interactive relationship between transportation and land use, just considering them as input and output of the system separately ${ }^{[4]}$. University of North Carolina and Curtis established a evaluation system on coordinated relationship between transportation and land use regarding to the distributed and low-density development mode for some large cities in U.S. That is helpful reference to construct the evaluation index system between rail transit and its surrounding land use in high-density cities of China ${ }^{[5-6]}$. In conclusion, the current studies on relationship evaluation between urban transportation and land use are concentrated on the macro level, so coordinated development discussion of urban rail transit and land use are mainly qualitative analysis ${ }^{[7-8]}$.

In the implementation stage, TOD programs may not carried out strictly accordance with the standard planning scheme, and deviated from the coordinated planning of rail transportation and land use due to different benefits of government, real estate developers and other departments. In reality, it turns to be a transit related development (TRD), rather than transit oriented development. In different stages of construction period, tracking survey on implementation effects is necessary for 
coordination evaluation. In this paper, micro evaluation on coordination relationship between mass rail transit and its surrounding land use has some theoretical and practical significance. The urban mass rail transit and land use based on TOD are shown in Fig. 1.

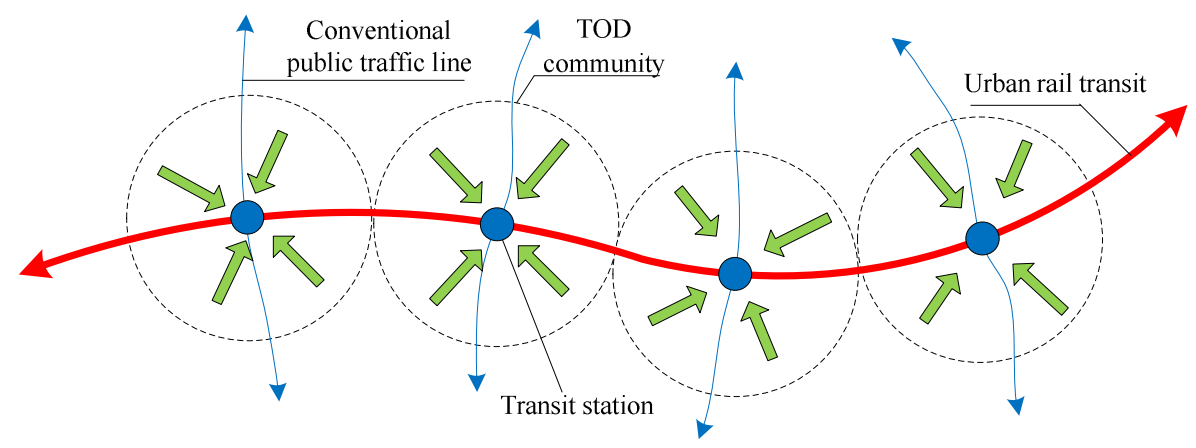

Fig. 1 Urban mass rail transit and TOD area land-use

\section{Evaluation methods selection and principles}

Evaluation object selected in this paper are the urban rail transit and its surrounding land use named TOD community along the route. Land development is guided by the mass rail transit. Therefore, mass rail transit is considered as a system input, land use of the TOD community as a system output, and validity of the system input-output is the extent of the coordinated degree between urban rail transit and land use of TOD community. Firstly, representative indexes are selected from the two systems to establish the evaluation index system. The input-output relationship between mass rail transit and land use is described in Fig. 2.

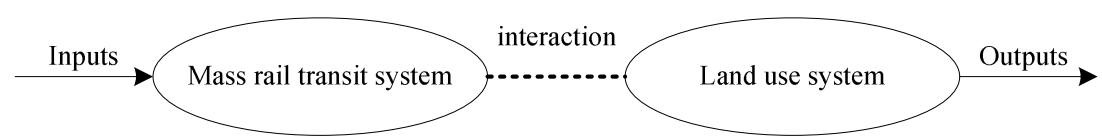

Fig. 2 Urban mass rail transit and TOD area land use

\section{Evaluation methods selection}

There are analytic hierarchy process, fuzzy comprehensive evaluation method, value function method and data envelopment analysis in multi-objective decision making to assess a complex system. Data envelopment analysis was proposed by Charnes, Coopor and Rhodes in 1978. The principle of the method considers every evaluation object as a decision making units (DMU), maintains input or output of $D M U$ unchanged, and get the overall analysis of the ratio of input to output. Linear programming technique can be employed to determine the relatively valid production frontier, and then the individual $D M U$ are projected onto valid frontier. Finally, the relatively validity of $D M U$ is determined according to distance of the $D M U$ deviated from the valid frontier.

There are four reasons for DEA method selected in this paper. Firstly, it can adapt to the evaluation index system which has a multiple input and output on the comprehensive validity evaluation. Especially, it has an absolute advantage since it can access validity of multi-objective decision-making of complex system. Secondly, making index being dimensionless of input and output data are not needed in DEA method. Consequently, it cannot be affected by different measurement units of the indexes, and thus more accurate. Thirdly, the model itself can calculate the weight. It does not require a pre-given weight of the input and output indexes, excluding a lot of subjective factors. It has irreplaceable advantages compared with traditional method, and improves the accuracy of evaluation results greatly. Last, DEA method can not only judge the validity of $D M U$, but also further analyze the cause of the $D M U$ invalid, and obtain countermeasures using DEA projection principle.

The evaluation procedure frame of coordinated relationship between mass rail transit and TOD communities based on DEA method is proposed in Fig. 3. 


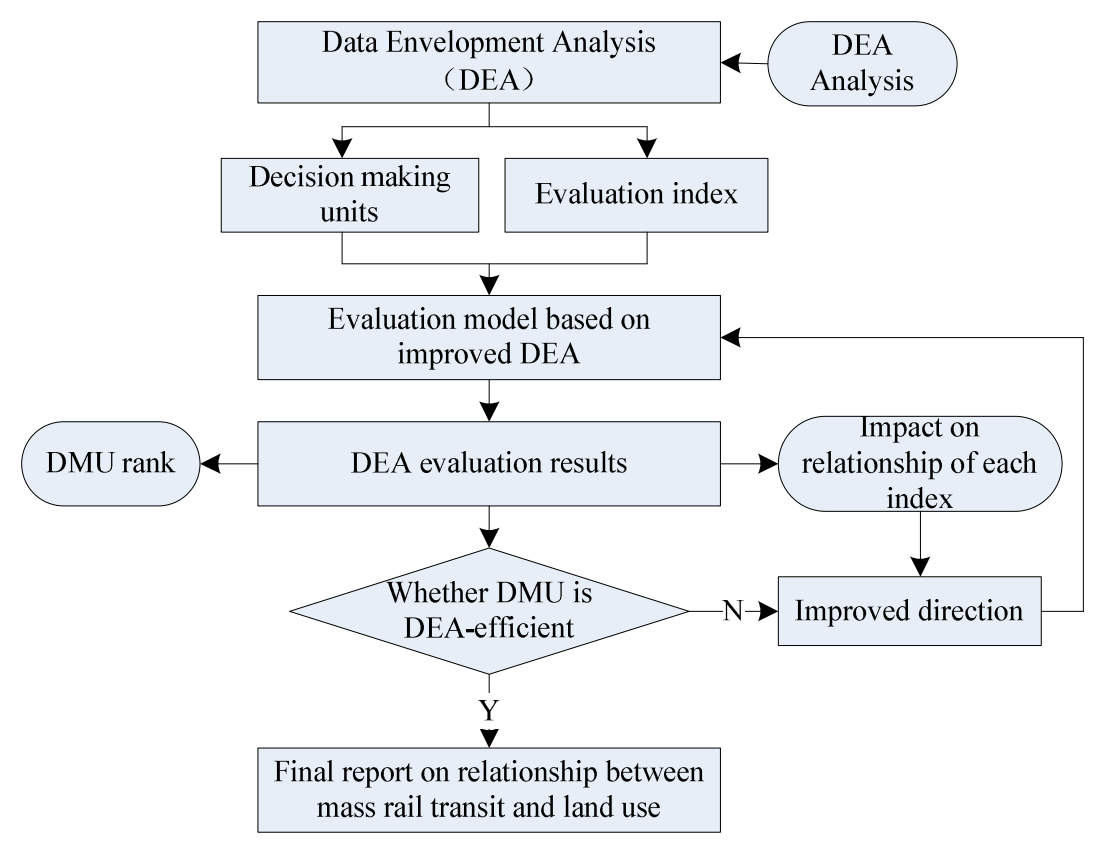

Fig. 3 Evaluation procedure frame of coordinated relationship

\section{Principles of establishing evaluation index system}

The TOD mode is a key way to achieve sustainable development between urban rail transit and land use though integrating them. According to the features of urban rail transit and TOD communities along the route, the selection of the evaluation indexes should follow there principles. Firstly, the indexes selected should be representative. Although there are many indexes to characterize urban rail transit system and land use of TOD community system, those factors which has a deeper impact, and close to the coordinated development should be emphasized. Meanwhile, factors should be able to fully reflect the degree of implementation of land use based on TOD mode, in order to determine whether the land use of TOD community along the route is adapted to the rail transit system, or coordinated development is achieved, that is to avoid the waste of rail transport resources due to inadequate development, and prevent from exceeding the supply of rail transit because of excessive development. Secondly, DEA method does not take into account interaction among the indexes. Because ignoring the correlation among the indexes will reduce the accuracy of the evaluation results. Thus, diversity of the evaluation indexes should be ensured, at the same time, strong correlation of the internal indexes in rail transit system and the TOD community land use system should be avoided ${ }^{[9]}$. Last, we should ensure that the index data is available and able to be quantified which is also important.

\section{Selection of evaluation indexes}

The evaluation indexes are selected based on the principles that can be seen from Tab.1. There are six indexes from mass rail transit system and five indexes from land use of TOD community selected in the evaluation index system at last.

\section{Urban mass rail transit system}

1) Average transfer time is used for the evaluation of transfer efficiency between rail transit and bus transit. Mass rail transit and bus are the main trip modes for TOD community residents. Coordinated development of between the rail and bus should have a highly efficient transfer to reduce residents time-consuming. 2) The average time for the TOD residents travelling from home to the transit station is used for evaluating the convenience of transit service facilities in TOD community. The coordinated TOD communities should have perfect slow transport system where residents can quickly and easily reach the transit station by foot or bicycle. 3) Utilization rate of the transit station capacity which is the ratio of the average transit flow per hour to the passenger capacity of transit station is used for evaluating usage of transit resources which are used by TOD community residents. Coordinated bus resource utilization rate is high and does not exceed the 
passenger bearing capacity of the station. 4) Split rate of bus trips is for the evaluation of TOD resident's choice to travel by bus. Coordinated TOD community should have a higher transit split rate, because public transport should be the first choice of TOD community residents. 5) Vehicle kilometers travelled (VKT) per capita is used to evaluate impact of car trips in TOD community on environment. Residents of TOD community under the coordination state will choose low-carbon environmentally friendly transit trip instead of being dependent on vehicles. 6) Trip distance per capita is used to evaluate the mixed land use effect on residents' trip of TOD community. On the coordinated state, commercial, residential, official and different properties of lands are aggregated, and some trips are within TOD community, thus reducing the total traffic demand.

Tab.1 Evaluation Index System of Coordinated Relationship

\begin{tabular}{|c|c|c|}
\hline System & Coordinated performance & Index \\
\hline \multirow{6}{*}{$\begin{array}{l}\text { Urban } \\
\text { mass rail } \\
\text { transit }\end{array}$} & $\begin{array}{l}\text { Efficient transfer between mass rail transit } \\
\text { and buses }\end{array}$ & Average transfer time (min) \\
\hline & $\begin{array}{c}\text { Convenient path from home to transit } \\
\text { station in TOD community }\end{array}$ & $\begin{array}{l}\text { Average time from houses to stations } \\
\text { (min) }\end{array}$ \\
\hline & $\begin{array}{l}\text { No wasting public transport resources and } \\
\text { no more than the passenger capacity of } \\
\text { transit station }\end{array}$ & $\begin{array}{l}\text { Utilization rate of the transit station } \\
\text { capacity }(\%)\end{array}$ \\
\hline & Encourage public transit ridership & Split ratio of bus trips $(\%)$ \\
\hline & $\begin{array}{c}\text { Reduce emissions from cars to protect the } \\
\text { environment }\end{array}$ & $\begin{array}{c}\text { Vehicle kilometers travelled per } \\
\text { capita } \\
(\mathrm{km} \text { per capita })\end{array}$ \\
\hline & $\begin{array}{l}\text { Reduce unnecessary trips to control the } \\
\text { total traffic demand }\end{array}$ & $\begin{array}{c}\text { Trip distance per capita } \\
(\mathrm{km} \text { per capita })\end{array}$ \\
\hline \multirow{5}{*}{$\begin{array}{l}\text { Land use } \\
\text { of TOD } \\
\text { community }\end{array}$} & $\begin{array}{l}\text { Make full use of land resources to prevent } \\
\text { the spread in a low density }\end{array}$ & $\begin{array}{c}\text { Population density } \\
\text { (people per square kilometers) }\end{array}$ \\
\hline & Jobs-Housing balance & Jobs-housing ratio $(\%)$ \\
\hline & High density development & FAR (floor area ratio) \\
\hline & $\begin{array}{l}\text { Comfortable environment for walking and } \\
\text { bicycle }\end{array}$ & Non-motor lane area ratio $(\%)$ \\
\hline & $\begin{array}{l}\text { Mixed land use to layout different } \\
\text { function land }\end{array}$ & Non-residential land area ratio (\%) \\
\hline
\end{tabular}

\section{Land use system}

1) Population density is population size in the unit area. It can reflect the intensive use of the limited land resources. TOD community under coordinated status is a vibrant gathering place with a high population density, which can inhibit disordered extension of low density land use effectively. 2) Jobs-housing ratio refers to the proportion of the number of working positions taking the total number of residents in the community. It is used to evaluate whether the employment and house have achieved a balance. Coordinated TOD community has a higher ratio to reduce long-distance traffic demand, hence alleviate traffic congestion effectively. 3) Floor area ratio (FAR) refers to the rate of total floor area to the TOD community land area. It is used to evaluate the degree of land development. Coordinated TOD community should show the high-density, high-strength characteristics. It provides adequate bus traffic for passengers and does not exceed the traffic supply capacity of the urban main line of bus transit. 4) Non-motor lane area ratio is used for evaluating the construction of walking lane, bicycle lane and other slow traffic system in the TOD community. Coordinated TOD community has perfect walking lane, bicycle lane to access the bus station in order to facilitate the residents taking the bus. 5) Non-residential land area ratio can reflect the 
degree of mixed land use in the TOD community. On the coordination state, TOD community should make a mixed development of commercial, residential, office and other functional properties land. It is to avoid living in a single land use pattern, resulting in residents only working or shopping in the central area and living in the community.

\section{Conclusions}

Through analyzing the suitable methods and principles of evaluation index system on relationship between urban rail transit and land use based on TOD mode, an evaluation procedure frame was proposed based on DEA model, and the evaluation index system was set up. The whole research hadn't taken into an actual case to verify the evaluation index system, so further research is needed.

\section{Acknowledgments}

This work was partially supported by National Science Foundation of China (Project Nos. 71173061, 70903018 and 51008002), State Key Laboratory of Subtropical Building Science South China University of Technology (Project Nos. 2011KB20) and Scientific Research Innovation Foundation in Harbin Institute of Technology (HIT. NSFIR. 2011126).

\section{References}

[1] Waddell P, Ulfarsson G F, Franklin J P, et al. Transportation Research Part A. 2007, 41: 382-410.

[2] Yim K K, Wong S C, Anthony Chen, et al. Transportation Research Part C. 2011, 19: 351-362.

[3] Chu Haoran, Wang Jiangyan, Zhou Yanhu, et al. Urban Transport of China. 2008, 6(5): 30-35. (in Chinese)

[4] Yang Liya, Shao Chunfu, Nie Wei, et al. Journal of Beijing Jiaotong University. 2007, 31(3): 6-9. (in Chinese)

[5] University of North Carolina. Report on the Theory and Practice of Integrated Land Use and Urban Transportation. 2006.

[6] Carey Curtis. Planning Practice and Research. 2008, 23(3): 285-302.

[7] Chiu Y H, Huang C W, Ma C M. European Journal of Operational Research. 2011, 209(2): 95-103.

[8] Chuan Ding. Harbin Institute of Technology Thesis for the Mater Degree of Engineering. 2011. (in Chinese)

[9] Zhang Junrong, Guo Yaohuang. Systems Engineering-Theory Methodology Application. 2004, 13(6): 520-523. (in Chinese) 